\title{
Comparison of Quadriceps Exercise Modalities on Pain, Muscle Strength, Function, and Balance in Bilateral Knee Osteoarthritis
}

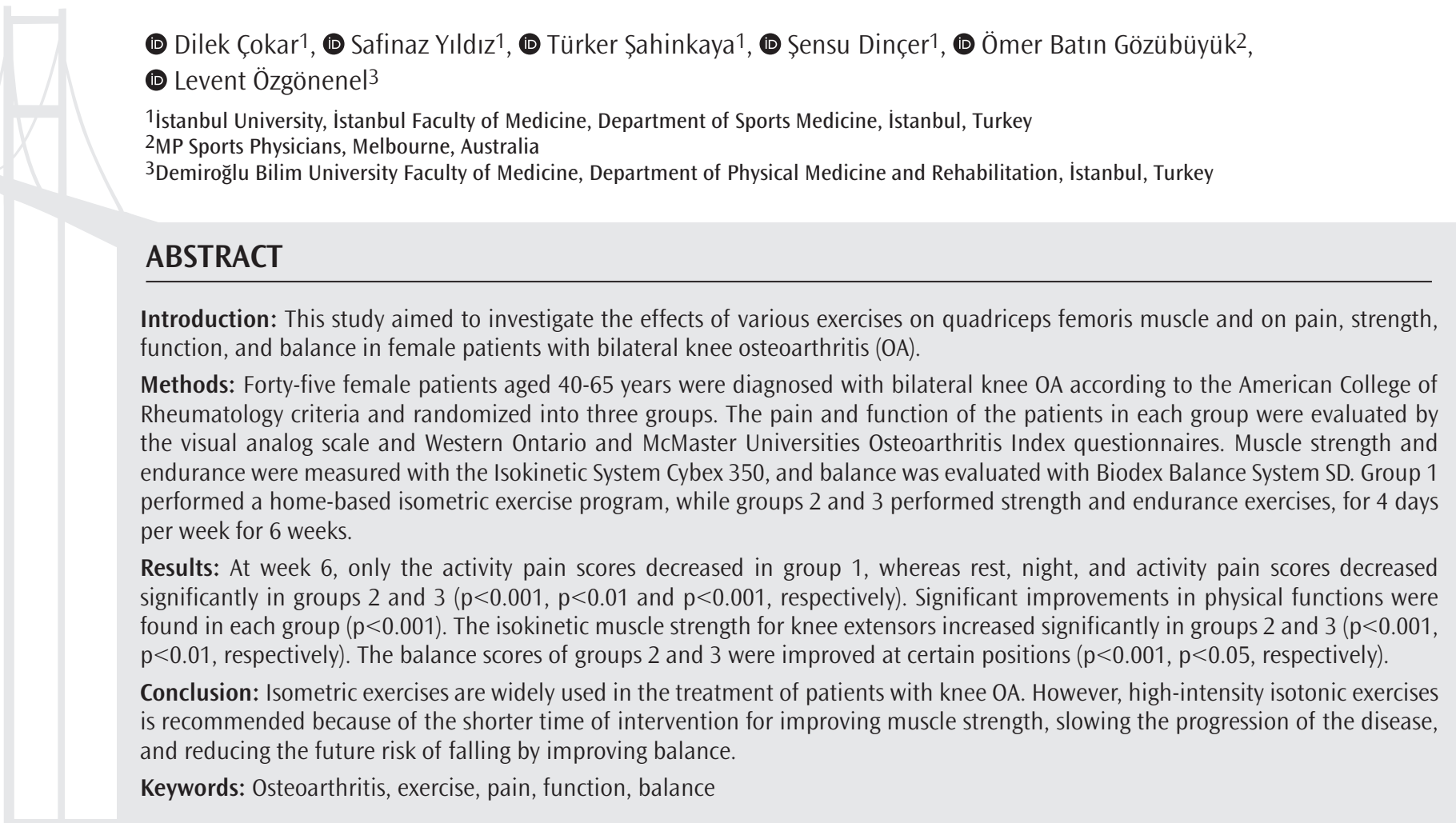

\section{Introduction}

Osteoarthritis (OA) is a progressive state of weight-bearing joints such as the knee and is common in geriatric patients (1). Knee OA is commonly associated with quadriceps femoris muscle weakness, functional impairment, reduced quality of life, and increased morbidity and mortality (2). Age-related sarcopenia and reduction in muscular strength result in the reduction of activities of daily living and mobility of the patients and increases falling risk. It also reduces proprioception of the knee joint, which further contributes to this process. OA has been shown to affect muscle strength and mechanoreceptors at the knee joint, thus increasing the risk of balance problems in patients $(3,4)$.

The initial treatment for $\mathrm{OA}$ includes medications, lifestyle modification, and rehabilitation. This treatment aims to manage pain, preserve and improve joint functioning, provide functional independence, and improve quality of life (2,5-7). Exercise treatment is one of the critical components of the rehabilitation program, as emphasized by numerous studies $(5,6,8)$. However, the target muscle group for an exercise program, type and intensity, and outcomes of such programs on patients' symptomatology have been debated. Most commonly, the quadriceps muscle group was the target for a specific exercise program, but a broader lower extremity program, as well as aerobic programs, has been studied. A specific exercise program targeting the quadriceps muscle group was most effective in reducing patients' symptoms (9). There is no definite consensus on the type, dose, and effect of exercise for the quadriceps femoris muscle on parameters such as pain, physical function, strength, and balance in $\mathrm{OA}(5,9)$.

This study aimed to investigate the effects of different types of quadriceps femoris muscle exercises with varying intensities on pain, 
Çokar et al. Quadriceps Exercises in Patients with Gonarthrosis

muscle strength, physical function, and balance of female patients with bilateral knee OA.

\section{Methods}

The study recruited patients with newly diagnosed $\mathrm{OA}$ of the knee. Selection criteria were based on the clinical and radiological criteria defined by the American College of Rheumatology for knee OA. In addition, patients at grade 2 and 3, according to the Kellgren-Lawrence Classification, were included, and these patients in each group had homogeneous characteristics. Female patients aged 40-65 years with a diagnosis of bilateral knee OA who were admitted to the outpatient physical medicine and rehabilitation clinics of İstanbul University Faculty of Medicine and Şişli Florence Nightingale Hospital between March 2016 and December 2016 were included in the study.

The Clinical Research Ethics Committee of İstanbul University, İstanbul Faculty of Medicine (approval number: 2016-249, date: 29.02.2016) approved the study. This study was supported by İstanbul University Scientific Research Projects Unit (project no: 22047).

Patients who had a history of knee or hip surgery, who received an intraarticular injection in the previous 3 months, whose knee flexion range was $<100^{\circ}$ or with an extension loss $>10^{\circ}$, patients with a neurological disorder that affects lower limb musculature, or patients with an inflammatory rheumatologic condition were excluded.

In total, 46 patients volunteered for the study and signed the informed consent forms. One patient withdrew from the study because of family commitments. The remaining 45 patients were divided into three groups according to the order of admittance to the clinic. Patients were assessed with the same measures before and after the 6 -week treatment. The assessments included knee range of motion measurement, visual analog scale (VAS), Western Ontario and McMaster Universities Osteoarthritis Index (WOMAC), knee strength and endurance assessment using an isokinetic dynamometer, and balance assessment using a Biodex Balance System.

Patient report forms: Each patient report form included demographic information including age, weight, height, history and family background, patient occupation, knee range of motion values, and progress charts for each session.

Assessment of pain levels: VAS was used to assess the patients' level of pain. Three measures were noted to assess pain at rest, with physical activity, and at night. Patients were provided with a $10 \mathrm{~cm}$ long horizontal scale, and they were asked to put a mark on this scale to represent their pain level. The scale was described to patients as "0" representing a state of no pain at all and "10" representing an unbearable pain. The distance was then measured and noted.

WOMAC index: This index is widely used by clinicians to assess pain, stiffness levels, and functional status of patients with OA. The index consists of 24 questions and three main sections. Pain is assessed with 5 , stiffness with 2, and physical functioning with 17 questions in these sections. Higher scores in the WOMAC index represent increased pain and stiffness and worsened physical functioning $(10,11)$.
Measurement of muscular strength and endurance: Muscular strength and endurance of the knee flexor and extensor muscle group were assessed with a Cybex $350^{\circledR}$ isokinetic dynamometer system. The patients warmed up with a stationary bike for $7 \mathrm{~min}$ at $65 \mathrm{rpm}$ with an intensity of $2 / 10$. The muscular strength of the knee was measured for five repetitions after a trial of three maximal knee flexion and extension movements at a low angular velocity $\left(60^{\circ} / \mathrm{s}\right)$. The average peak torque, peak torque/body weight, total work done, and total work/body weight values of the five repetitions were noted. The same exercise specialist performed the measurements throughout the study and provided patients verbal motivation during the tests. Endurance was then measured using a high angular velocity $\left(180^{\circ} / \mathrm{s}\right)$ for 15 repetitions after a trial of five repetitions. The average peak torque, peak torque/body weight, total work done, and total work/body weight values of the 15 repetitions noted. Both extremities were measured (12).

Measurement of balance: The static balance of the patients was measured using the Biodex Balance System ${ }^{\circledR}$, which was regularly calibrated each year. The test platform was set to the static mode. The patients were asked to maintain a balanced stance position at these settings: i) eyes open, knees are at full extension; ii) eyes closed, knees at full extension; iii) eyes open, knees bent by approximately $30^{\circ}$; and iv) eyes closed, knees bent by approximately $30^{\circ}$. The anteroposterior index, mediolateral index, and overall index were assessed using the internal post-processing algorithm of the device. Each position was tested three times, and an average value representing each index was noted (13).

\section{Treatment Groups}

\section{Isometric exercise group (group 1)}

Isometric knee exercises were prescribed as a home-based exercise program. The patients were asked to perform maximal isometric knee extension exercise for $5 \mathrm{~s}$ and repeat this 10 times while sitting with their knees extended. A towel was placed under the exercising knee to facilitate the knee extension at this position. Exercise intensity was assessed via the 0MNI 0-10 scale ( 0 as "extremely easy" to 10 as "extremely hard") (14). When perceived exertion was reduced to $\leq 5$ on a 10-point scale, they were asked to perform 20 repetitions instead of 10. Patients performed these exercises four times per week within 6 weeks. Each patient was followed up via phone calls, which reviewed the technique of exercise, total exercise duration and frequency, and rate of perceived exertion.

\section{Strength exercise group (group 2)}

Patients were allocated into a high-intensity low-repetition isotonic strength exercise program supervised by a physiotherapist for 6 weeks (Table 1). Patients performed these exercises four times per week. The intensity was determined by the 1-RM method, and patients performed the exercise for five repetitions at an intensity of $80 \%$ of $1-\mathrm{RM}$ during the first 3 weeks and five repetitions at 90\% during the second 3 weeks (15). Sandbags were used to achieve the desired intensity. There were no pain flare-ups during or after the high-intensity sessions. 


\section{Endurance exercise group (group 3)}

Patients were allocated into a low-intensity high-repetition isotonic endurance exercise program (Table 1). Patients performed these exercises four times per week. group 3 performed the same exercise as group 2 , with a different intensity and repetition. The patients performed the exercise for 20 repetitions at an intensity of $40 \%$ of 1-RM during the first 3 weeks and for 20 repetitions at 50\% during the second 3 weeks (15). Sandbags were used to achieve the desired intensity.

\section{Statistical Analysis}

Statistical analysis of the data was performed with SPSS version $21.0^{\circledR}$ (Statistical Package for Social Sciences). Data normality was assessed using the Shapiro-Wilk test, which showed a normal distribution. Therefore, parametric tests were used for further analysis. $\mathrm{P}<0.05$ was set as a significance threshold for all values. A One-Way analysis of variance test was used to assess between-group differences, and Bonferroni correction was applied. Paired sample t-test was used to assess within-group differences before and after treatment. A mean difference was also calculated before and after treatments.

\section{Results}

The average age, height, and weight of the groups were comparable (Table 2). Activity pain reduced significantly after the exercise therapy in group $1(p<0.001)$. Activity pain $(p<0.001)$, resting pain $(p<0.01)$, and night pain $(p<0.001)$ reduced significantly in groups 2 and 3 (Table 3$)$. Average pain, stiffness, and physical functioning values of the WOMAC index reduced significantly in group $1(p<0.05, p<0.01$, and $p<0.001$, respectively) and in group 2 ( $p<0.001, p<0.01$, and $p<0.001$ respectively). The average pain $(p<0.001)$ and physical function $(p<0.001)$ values of the WOMAC index reduced significantly in group 3 , whereas the stiffness value did not change (Table 3).

In group 1, isokinetic muscle strength and endurance measures (peak torque, peak torque/body weight, total work done, and total work/body

\section{Table 1. Applied exercises}

\begin{tabular}{|l|l|}
\hline Exercises for group 1 & Exercises for groups 2 and 3 \\
\hline - Hamstring stretching & - Hamstring stretching \\
\hline - Quadriceps femoris stretching & - Quadriceps femoris stretching \\
\hline - Supine straight leg raise & - Supine straight leg raise \\
\hline - Supine knee press & - Supine short-arc knee extension \\
\hline - Supine ball squeeze in between & - Knee extension while sitting \\
\hline legs & - Short-arc knee extension while sitting \\
\hline - Straight leg raise in side-lying & - Sulion \\
\hline
\end{tabular}

Table 2. Demographic data

\begin{tabular}{|c|c|c|c|c|}
\hline Parameters & $\begin{array}{l}\text { Group } 1 \\
(\text { mean } \pm \text { SD) }\end{array}$ & $\begin{array}{l}\text { Group } 2 \\
(\text { mean } \pm \text { SD) }\end{array}$ & $\begin{array}{l}\text { Group } 3 \\
(\text { mean } \pm S D)\end{array}$ & p \\
\hline Age (year) & $48.20 \pm 7.5$ & $53.6 \pm 9.1$ & $52.4 \pm 6.7$ & 0.121 \\
\hline Height (m) & $1.63 \pm 0.5$ & $1.59 \pm 0.7$ & $1.60 \pm 0.5$ & 0.148 \\
\hline Body weight (kg) & $82.6 \pm 13.9$ & $78.0 \pm 10.3$ & $82.7 \pm 5.9$ & 0.383 \\
\hline $\begin{array}{l}\text { Body weight (after } \\
6 \text { weeks) (kg) }\end{array}$ & $82.2 \pm 14.2$ & $78.3 \pm 10.7$ & $82.5 \pm 7.06$ & 0.515 \\
\hline
\end{tabular}

weight) were not different from baseline in the knee extensor muscle group of both extremities, whereas the peak torque of the flexor muscle group of both knees $(p<0.05)$ and the peak torque/body weight of the left knee $(p<0.05)$ showed significant changes (Table 4). In group 2, all measures from the isokinetic assessment showed remarkable increases in both extensor and flexor muscle group in both knees (Table 4, 5). In group 3, extensor muscles had increased maximal strength, such as peak torque [right knee $(p<0.05)$, left knee $(p<0.01)$ ] and peak torque/body weight $(p<0.01)$, in both knees (Table 4). Moreover, the peak torque, peak torque/body weight, total work done, and total work/body weight showed remarkable changes for the flexor muscle group of the left knee $(p<0.05)$ (Table 5).

Balance assessment of group 1 did not result in significant changes in either of the scores. Group 2 showed significant improvements in "eyes open, knees in extension" ( $p<0.001)$, "eyes open, knees in flexion" $(p<0.05)$, and "eyes closed, knees in flexion" conditions $(p<0.001)$. However, no significant changes were observed in the "eyes closed, knees extended" condition. In group 3, only "eyes closed, knees in flexion" and "eyes open, knees in flexion" balance conditions showed improvements $(p<0.05)$ (Table 6).

\section{Discussion}

The management of knee $\mathrm{OA}$ involves medical treatment, lifestyle modification, and rehabilitation. Exercise is one of the critical components of the rehabilitation program $(5,6,8)$. The effectiveness of specific exercises for the quadriceps femoris muscle is widely accepted. However, the type, intensity, duration, and frequency of the planned exercise are still not established. Thus, this study investigated the effects of different types and intensities on strength, pain, function, and balance.

Our results revealed that the VAS score only improved for "pain during activity" in group 1, whereas all types of pain improved in groups 2 and 3. These results are consistent with the literature. Additionally, all three groups have significantly improved pain, stiffness, and daily physical functioning scores in the WOMAC index compared with the pretreatment values. These results also support the literature data (6,9,16-21).

Fransen et al. (18) compared the effect of knee flexor and extensor muscle strength exercises in reducing pain and increasing physical function in patients with knee OA. They found that the increase in knee extensor muscle strength is more related to improvement in both parameters than to flexor muscle strength. Moreover, they reported that exercise treatment is more effective in decreasing pain than analgesic medication. They also noted that exercise therapy was more effective than analgesic drugs for reducing pain. Our study revealed that pain decreased and physical function improved in all types of muscle strengthening that were applied to the extensor muscle group. Juhl et al. (9) examined the effect of exercise type and dose on pain and disabilities in knee OS in a systematic review and meta-regression analysis of randomized controlled trials. They suggested that an optimal exercise program for knee $\mathrm{OA}$ is performed at least three times a week. Pelletier et al. (19) also reported that an 8-week exercise program consisting of 
Table 3. Comparison of VAS and WOMAC scores before and after exercise

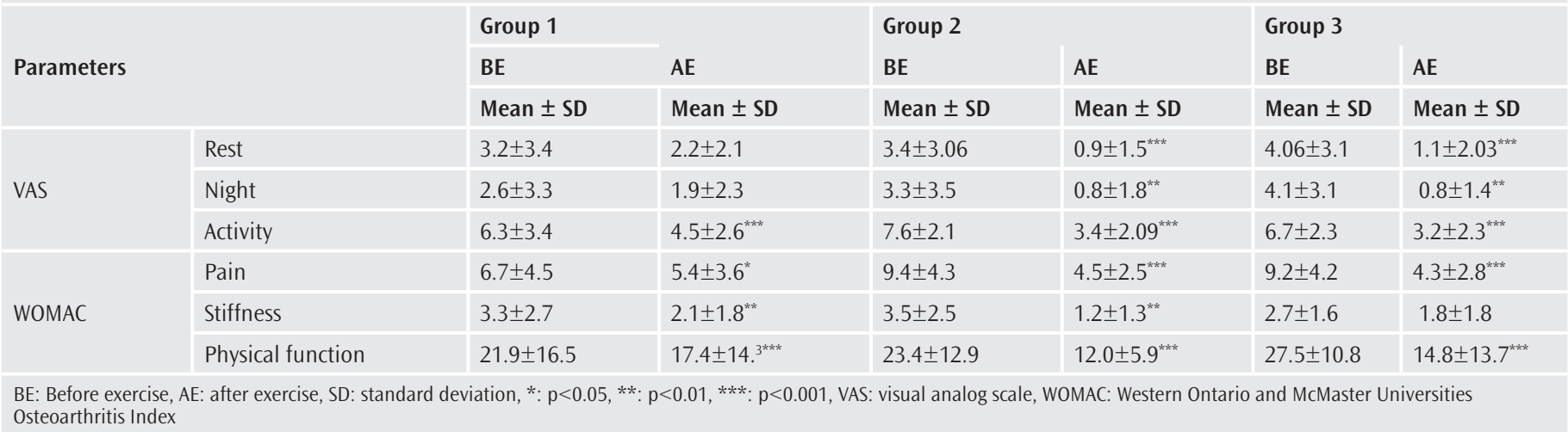

Table 4. Isokinetic assessment of knee extensor muscle group before and after exercise

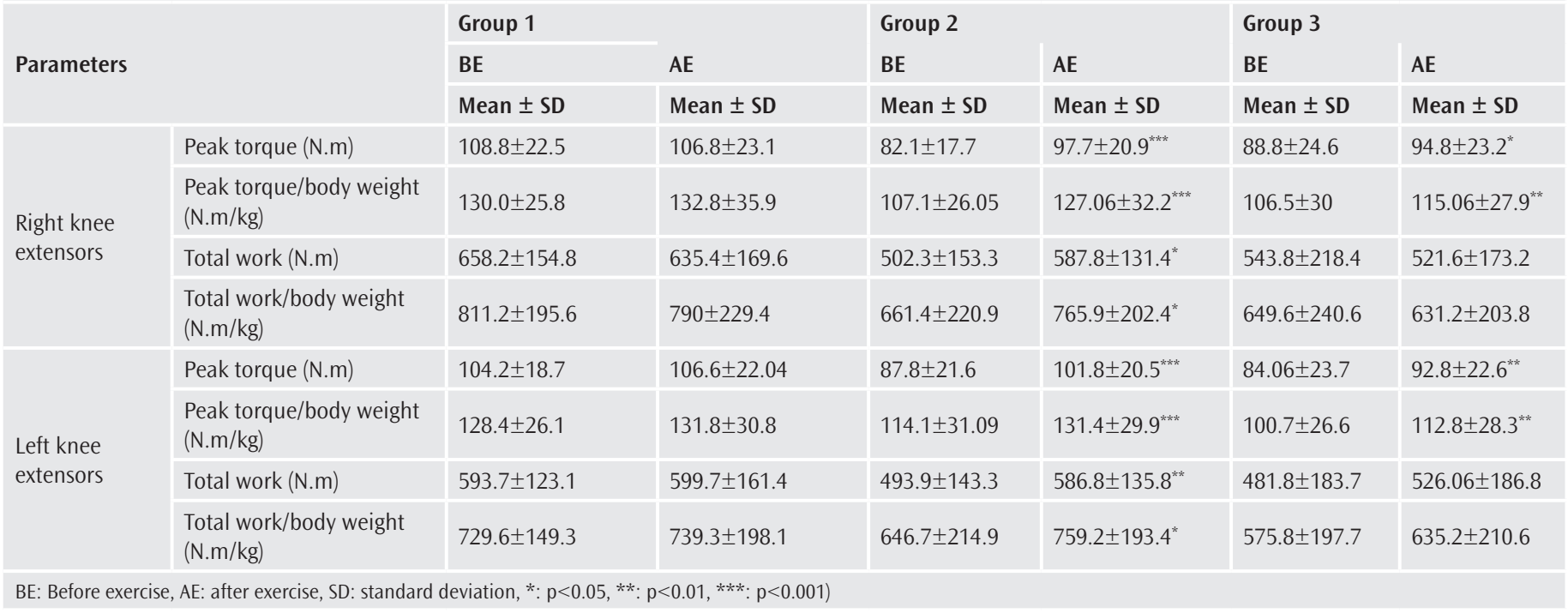

Table 5. Isokinetic assessment of knee flexor muscle group before and after exercise

\begin{tabular}{|c|c|c|c|c|c|c|c|}
\hline \multirow{2}{*}{ Parameters } & & \multicolumn{2}{|l|}{ Group 1} & \multicolumn{2}{|l|}{ Group 2} & \multicolumn{2}{|l|}{ Group 3} \\
\hline & & $\mathrm{BE}$ & $\mathrm{AE}$ & $\mathrm{BE}$ & $\mathrm{AE}$ & BE & $\mathrm{AE}$ \\
\hline \multirow{2}{*}{$\begin{array}{l}\text { Right knee } \\
\text { flexors }\end{array}$} & $\begin{array}{l}\text { Peak torque/body weight } \\
(\mathrm{N} . \mathrm{m} / \mathrm{kg})\end{array}$ & $76.4 \pm 13.4$ & $83.2 \pm 18.1$ & $67.06 \pm 16.8$ & $83.6 \pm 22.7^{* * *}$ & $73.2 \pm 19.5$ & $77.6 \pm 20.6$ \\
\hline & Total work (N.m) & $446.1 \pm 93.6$ & $474.2 \pm 130.2$ & $373.6 \pm 116.3$ & $478.8 \pm 192.3^{* *}$ & $407.9 \pm 121.9$ & $441.06 \pm 137.5$ \\
\hline \multirow{3}{*}{$\begin{array}{l}\text { Left knee } \\
\text { flexors }\end{array}$} & Peak torque (N.m) & $64.1 \pm 11.5$ & $69.0 \pm 15.2^{*}$ & $52.5 \pm 8.8$ & $64.4 \pm 13.6^{* * *}$ & $58.5 \pm 17.3$ & $662 \pm 20.3^{*}$ \\
\hline & $\begin{array}{l}\text { Peak torque/body weight } \\
(\mathrm{N} . \mathrm{m} / \mathrm{kg})\end{array}$ & $77.8 \pm 11.5$ & $84.7 \pm 18.5^{*}$ & $68.4 \pm 12.7$ & $83.7 \pm 19.1^{* * *}$ & $70.3 \pm 19.2$ & $80.4 \pm 25.2^{*}$ \\
\hline & Total work (N.m) & $473.6 \pm 103.8$ & $511 \pm 128.01$ & $383.1 \pm 119.7$ & $464.4 \pm 138.8^{* *}$ & $406.1 \pm 134.5$ & $477.8 \pm 175.5^{*}$ \\
\hline
\end{tabular}

three times weekly sessions of quadriceps femoris strength exercises (knee flexion-extension) reduced pain and improved daily functions in patients with knee OA. In the present study, we determined the duration and frequency of exercise as a 6-week exercise program consisting of four sessions per week, which is consistent with the literature. At the end of this period, we found significant improvements in pain and physical function in all groups. 
Table 6. Comparison of balance scores before and after exercise

\begin{tabular}{|l|l|l|l|l|l|}
\hline & Group 1 & Group 2 & & Group 3 \\
\hline \multirow{2}{*}{ Parameters } & BE & AE & BE & AE & BE \\
\hline EOKE & Mean \pm SD & Mean \pm SD & Mean \pm SD & Mean \pm SD & Mean \pm SD \\
\hline ECKE & $0.50 \pm 0.13$ & $0.48 \pm 0.20$ & $0.62 \pm 0.14$ & $0.43 \pm 0.13^{* * *}$ & $0.74 \pm 0.43$ \\
\hline EOKF & $1.12 \pm 0.45$ & $0.91 \pm 0.32$ & $1.40 \pm 0.82$ & $1.12 \pm 0.46$ & $1.79 \pm 1.13$ \\
\hline ECKF & $0.74 \pm 0.38$ & $0.71 \pm 0.22$ & $0.92 \pm 0.42$ & $0.70 \pm 0.25^{*}$ & $1.17 \pm 0.65$ \\
\hline
\end{tabular}

EOKE: Eyes open knee in extension, ECKE: eyes closed knee in extension, EOKF: eyes open knee in flexion, ECKF: eyes closed knee in flexion, BE: before exercise, AE: after exercise, SD: standard deviation, *: $p<0.05, * *: p<0.01, * * *: p<0.001$

The isokinetic strength of the knee extensor muscle group in group 1 did not show significant changes in our study. This suggests that a 6-week home-based isometric knee exercise program does not significantly increase muscular strength in patients with knee OA. However, this could be an expected outcome, as the exercises were isometric, and isometric exercises should be performed for an extensive period to gain significant strength. In group 2, all isokinetic strength parameters improved significantly. We believe that these improvements are mainly due to neuronal adaptation, as 6 weeks is a relatively short duration to observe hypertrophy to its full extent. These results regarding both isometric and strength exercises also overlap with the physiological mechanisms expressed in a previous study (22).

Messier et al. (21) suggested that higher-intensity exercises worsen the knee pain, degenerate structures around the joint, increase the risk of injury, and may increase blood pressure of patients with knee OA. Raymond et al. (23) emphasized the positive effects of high-intensity progressive muscle strengthening exercises on muscle strength, physical function, depression, and quality of life in patients aged $>65$ years in a systematic review of 21 randomized controlled studies. Their results suggest that higher-intensity isotonic exercises are superior in gaining muscular strength; however, other types and intensities of exercises could be preferred for improving other parameters such as physical function, depression, and life quality index. We did not encounter risk events of high-intensity exercise in our study. Our results are consistent with the literature finding that supports the benefits of high-intensity isotonic exercise to strengthen knee muscles. We also showed that other types and intensity of exercises could improve other parameters such as pain reduction and physical function.

We investigated balance with both eyes open and closed and knees in extension and flexion separately. In group 1, none of these parameters had significant changes, and the other two groups had significant improvements. The strength exercise group showed an increase in several parameters (i.e., more tested positions) and higher significance values than the endurance exercise group. Strengthening the quadriceps femoris muscle becomes highly important in exercise therapy in $\mathrm{OA}$ because it is the most significant antigravity muscle of the lower extremity and has a significant role in maintaining balance. Bellew et al. (24) investigated a 12-week low-intensity quadriceps strength exercise program in the elderly and did not find an improvement in balance measures. These conflicting results in the literature are possibly due to methodological differences among studies, OA stage of the patients, exercise type, and intensity of the exercise sessions. Kim et al. (25) compared strength and balance exercises in different platforms in a 30knee OA patient cohort. After 6 weeks, no between-group difference was found in balance, but balance measures improved significantly within the groups before and after experiments. Our study supports the findings of Kim et al. (25) by showing improvements in balance measures in the strength exercise group.

\section{Study Limitations}

This study is not a double-blind placebo-controlled randomized study. However, for most patients presenting with knee OA, nonintervention may lead to dropouts and an unacceptable option for patients. As all groups showed improvement, there is a need for studies with larger study samples. Long-term exercises with different load intensities and duration should be addressed in future studies by increasing the sample size.

\section{Conclusion}

Exercise therapy should be performed in addition to controlling pain and inflammation in the treatment and rehabilitation of patients with $\mathrm{OA}$. Even though isometric exercises are widely used in this setting, to shorten the time of intervention for improving muscle strength, slowing disease progression, and reducing the risk of falling by improving balance in this population, we believe that including isotonic strength or endurance exercises to support the treatment should be considered.

Ethics Committee Approval: The Clinical Research Ethics Committee of İstanbul University, İstanbul Faculty of Medicine (approval number: 2016-249, date: 29.02.2016).

Informed Consent: In total, 46 patients volunteered for the study and signed the informed consent forms.

Peer-review: Externally peer-reviewed.

Authorship Contributions: Surgical and Medical Practices - D.C.., T.Ş., L.Ö.; Concept - D.C.., S.Y., L.Ö.; Design - D.Ç., S.Y., L.Ö.; Data Collection or Processing - D.Ç., S.Y., T.Ş., S..D., Ö.B.G., L.Ö.; Analysis or Interpretation - D.Ç., S.Y., T.S., S.D., Ö.B.G., L.Ö.; Literature Search - D.C.., S.Y., T.S., S..D., Ö.B.G.; Writing - D.Ç., S.Y., T.Ş., Ș.D., Ö.B.G., L.Ö.

Conflict of Interest: No conflict of interest was declared by the authors.

Financial Disclosure: This study was supported by İstanbul University Scientific Research Projects Unit (project number: 22047). 


\section{References}

1. Kutsal Gökçe Y, Kara M. Knee osteoarthritis. Sarıdoğan M, editor. Osteoarthritis 2007. p. 149-61.

2. Kirazlı Y. Current approach to the guidelines for the diagnosis and treatment of osteoarthritis. Turkish J Geriatr 2011; 14: 119-25.

3. Pereira HM, Campos TF de, Santos MB, Cardoso JR, Garcia M de C, Cohen M. Influence of knee position on the postural stability index registered by the Biodex Stability System. Gait Posture 2008; 28: 66872.

4. Pai YIC, Rymer WZ, Chang RW, Sharma L. Effect of age and osteoarthritis on knee proprioception. Arthritis Rheum 1997; 40: 2260-5.

5. Tuncer T, Çay HF, Kaçar C, Altan L, Atik OŞ, Aydin AT, et al. Evidencebased recommendations for the management of knee osteoarthritis: A consensus report of the Turkish league against rheumatism. Turkish Journal of Rheumatology 2012; 27: 1-17.

6. Anwer S, Alghadir A. Effect of isometric quadriceps exercise on muscle strength, pain, and function in patients with knee osteoarthritis: A randomized controlled study. J Phys Ther Sci 2014; 26: 745-8.

7. Hochberg MC, Altman RD, April KT, Benkhalti M, Guyatt G, McGowan J, et al. American College of Rheumatology 2012 recommendations for the use of nonpharmacologic and pharmacologic therapies in osteoarthritis of the hand, hip, and knee. Arthritis Care Res (Hoboken) 2012; 64: 465-74.

8. Andersen RE, Crespo CJ, Ling SM, Bathon JM, Bartlett SJ. Prevalence of significant knee pain among older Americans: Results from the Third National Health and Nutrition Examination Survey. J Am Geriatr Soc 1999; 47: 1435-8.

9. Juhl C, Christensen R, Roos EM, Zhang W, Lund H. Impact of exercise type and dose on pain and disability in knee osteoarthritis: A systematic review and meta-regression analysis of randomized controlled trials. Arthritis Rheumatol 2014; 66: 622-36.

10. Bellamy N, Buchanan WW, Goldsmith CH, Campbell J, Stitt LW. Validation study of WOMAC: A health status instrument for measuring clinically important patient relevant outcomes to antirheumatic drug therapy in patients with osteoarthritis of the hip or knee. J Rheumatol 1988; 15: 1833-40.

11. Tüzün EH, Eker L, Aytar A, Dașkapan A, Bayramoğlu M. Acceptability, reliability, validity and responsiveness of the Turkish version of WOMAC osteoarthritis index. Osteoarthritis Cartilage 2005; 13: 2833.
12. Brown LE, Stone MH. Isokinetic Exercise and Human Performance. Strength Cond J 2000; 22: 53-4.

13. Arnold BL, Schmitz RJ. Examination of balance measures produced by the biodex stability system. J Athl Train 1998; 33: 323-7.

14. Muyor JM. Exercise intensity and validity of the ratings of perceived exertion (Borg and OMNI Scales) in an indoor cycling session. J Hum Kinet 2013; 39: 93-101.

15. Bompa TO. Periodization: Theory and Methodology of Training. 6th Edition Med Sci Sport Exerc 2019; 51.

16. Snijders GF, Den Broeder AA, Van Riel PLCM, Straten VHHP, De Man FHR, Van Den Hoogen FHJ, et al. Evidence-based tailored conservative treatment of knee and hip osteoarthritis: Between knowing and doing. Scand J Rheumatol 2011; 40: 225-31.

17. Huang MH, Lin YS, Lee CL, Yang RC. Use of ultrasound to increase effectiveness of isokinetic exercise for knee osteoarthritis. Arch Phys Med Rehabil 2005; 86: 1545-51.

18. Fransen M, Crosbie J, Edmonds J. Physical therapy is effective for patients with osteoarthritis of the knee: A randomized controlled clinical trial. J Rheumatol 2001; 28: 156-64.

19. Pelletier D, Gingras-Hill C, Boissy P. Power training in patients with knee osteoarthritis: A pilot study on feasibility and efficacy. Physiother Can 2013; 65: 176-182.

20. Hernández Rosa U, Velásquez Tlapanco J, Lara Maya C, Villarreal Ríos E, Martínez González L, Vargas Daza ER, et al. Comparison of the Effectiveness of Isokinetic vs Isometric Therapeutic Exercise in Patients With Osteoarthritis of Knee. Reumatol Clin 2012; 8: 10-4.

21. Messier SP, Mihalko SL, Beavers DP, Nicklas BJ, Devita P, Carr JJ, et al. Strength training for arthritis trial (START): design and rationale. BMC Musculoskelet Disord 2013; 14: 208.

22. Hall JE. Guyton and Hall Textbook of Medical Physiology. 13th ed. 2017. p. 1085-95

23. Raymond MJ, Bramley-Tzerefos RE, Jeffs KJ, Winter A, Holland AE. Systematic review of high-intensity progressive resistance strength training of the lower limb compared with other intensities of strength training in older adults. Arch Phys Med Rehabil 2013; 94 : 1458-72.

24. Bellew JW, Yates JW, Gater DR. The initial effects of low-volume strength training on balance in untrained older men and women. J Strength Cond Res 2003; 17: 121-8.

25. Kim K, Lee HY, Lim SJ. Effects of increased standing balance on pain in patients with knee osteoarthritis. J Phys Ther Sci 2016; 28: 87-9. 